\title{
Timing of carotid endarterectomy and clinical outcomes
}

\author{
Bilal Azhar, Arsalan Wafi, James Budge, Ian Loftus \\ St Georges Vascular Institute, St Georges University London, London, UK \\ Contributions: (I) Conception and design: B Azhar, I Loftus; (II) Administrative support: All authors; (III) Provision of study materials or patients: All \\ authors; (IV) Collection and assembly of data: All authors; (V) Data analysis and interpretation: All authors; (VI) Manuscript writing: All authors; (VII) \\ Final approval of manuscript: All authors. \\ Correspondence to: Bilal Azhar, MBChB, BMedSci (Hons), MRCS. St Georges Vascular Institute, St Georges University Hospital NHS Trust, Ground \\ Floor, Corridor 10, Room 0.231, Cranmer Terrace, London, SW17 0RE, UK. Email: bilal1azhar@gmail.com.
}

\begin{abstract}
The timing of carotid endarterectomy (CEA) for symptomatic ipsilateral carotid artery stenosis has evolved in practice over time. Key landmark trials outlined the benefit of performing CEA in the recently symptomatic carotid artery stenosis, defined as revascularisation within 6 months of the index neurological event. Further evidence and sub-analysis demonstrate that performing CEA within 2 weeks of symptoms has the maximal benefit in reducing stroke free survival and is associated with a safe perioperative complication profile. This has translated into guideline recommendations and widespread clinical practice. The case for performing urgent CEA (within 48 hours of index neurological event) over early CEA (within 2 weeks) has been put forward and studied. Data examining perioperative complications for urgent CEA are mostly derived from retrospective single series studies. A moderate balance exists in the literature for the safety and risk of urgent CEA. Although many studies present acceptable perioperative stroke and mortality rates associated with urgent CEA, evidence still exists that the perioperative complications may not be insignificant. This is particularly the case if the presenting neurology is a stroke, rather than a transient ischaemic attack (TIA) or amaurosis fugax. This should be contextualised in the practice of modern aggressive medical therapy with dual antiplatelets and statins, with evidence suggesting a reduction in recurrent ischaemic events prior to surgical intervention. Careful patient selection, presenting neurology and medical therapy is likely to be a key feature in considering urgent CEA versus early CEA.
\end{abstract}

Keywords: Carotid endarterectomy (CEA); stroke; transient ischaemic attack (TIA); carotid artery stenosis

Submitted Jan 31, 2020. Accepted for publication May 13, 2020.

doi: $10.21037 /$ atm-20-1130

View this article at: http://dx.doi.org/10.21037/atm-20-1130

The disease burden arising from stroke remains a global epidemiologically important problem. One in eight strokes are fatal within 30 days and one in four are fatal within a year. It stands as the second largest cause of death globally. Thromboembolism arising from an ipsilateral carotid artery stenosis is an important aetiological process accounting for $20 \%$ of all strokes $(1,2)$.

Surgical management of the carotid artery stenosis introduced in the 1950's has evolved into an effective treatment in preventing stroke. The two landmark randomized controlled trials, the European Carotid Surgery Trial (ECST) (3) and the North American Symptomatic Carotid Endarterectomy Trial (NASCET) (4), have demonstrated the relative benefit of carotid endarterectomy (CEA) in the recently (within 6 months) symptomatic ipsilateral carotid artery stenosis. The findings from these trials translated into grade A recommendations from the American Heart Association guidelines for performing CEA for symptomatic $70-99 \%$ carotid artery stenosis within 6 months of an ipsilateral non-disabling carotid artery ischaemic event (5). Delaying operative intervention for 6-8 weeks after a cerebral event was thought to be beneficial at that time due to the perceived increased risk of haemorrhagic transformation and increased peri-procedural risk together with the belief that delaying CEA would allow the carotid plaque to stabilise $(6,7)$. Further evidence from 
pooled analysis of NASCET and ECST demonstrated contrary evidence (8). The maximal benefit in preventing future transient ischaemic attack (TIA) and stroke was shown to be in the first 2 weeks after the initial ischaemic event in these trials. Beyond 2 weeks, the benefit of CEA fell dramatically for men with $>69 \%$ stenosis. The 5 -year absolute risk reduction was $30.2 \%$ with a number needed to treat (NNT) of 3 to prevent 1 ipsilateral stroke if CEA was performed within 2 weeks (7). The NNT doubles to 6 if CEA is delayed between 2-4 weeks (7). In females, benefit was only seen by performing CEA for $>69 \%$ stenosis within 2 weeks (8). Studying the natural history of symptomatic carotid artery stenosis, the recurrent neurological event rate is highest in the earlier period following an ischaemic event. Stroke rate after a TIA is $6.7 \%$ at 2 days and $11.7 \%$ at 7 days (9). In a study of 163 patients with symptomatic carotid artery stenosis, the recurrent stroke rate was found to be $20.9 \%$ within 3 days, $6.7 \%$ between 3 and 7 days and $3.7 \%$ between 7 and 14 days (10). Early ( $<30$ days) $v$ s. delayed ( $>30$ days) CEA did not differ in the periprocedural stroke or death rate [relative risk: $0.92 ; 95 \%$ confidence interval (CI): 0.16-5.27; $\mathrm{P}=1.00]$ in further NASCET analyses (11), providing further support in performing CEA within 2 weeks. Naylor contextualised the argument for early (within 2 weeks) CEA with insights from a re-analysis of NASCET (12), ECST (13) and the Veteran Affairs trial (14). This analysis suggests that if CEAs are performed within 2 weeks even with a $10 \%$ perioperative stroke risk, at 5 years more strokes will have been prevented than by delaying CEA beyond 4 weeks with an associated $0 \%$ perioperative stroke risk $(7,15)$.

European and North American guidelines provided recommendations favouring early CEA ( $<2$ weeks) for symptomatic ipsilateral stenoses $(16,17)$. The UK National Stroke Strategy advocated performing CEA within 48 hours (urgent) in patients with stable neurology (18). Surveying practice within the United Kingdom reflected this guidance when analysing the UK National Vascular Registry (NVR). CEA was performed in only $10 \%$ of patients within 2 weeks of the index event in 2008, rising to $37 \%$ in 2009 and $58 \%$ in 2014 (19). The median delay from index symptom to CEA decreased from 22 days (IQR, 10-56 days) in 2009 to 12 days (IQR, 7-26 days) in 2014. In examining real world practice over time, the earlier concerns regarding increased peri-operative complication rates with early CEA were not found in this study. As the median time to CEA decreased over 6 years in the UK, no corresponding trend towards increasing peri-operative complications was observed. The overall postoperative 30-day stroke rate and death rates after CEA were $1.85 \%$ (95\% CI: $1.67-2.02$ ) and $0.83 \%$ (95\% CI: 0.71-0.94). The combined 30-day stroke and death rate post CEA was $2.31 \%$ (95\% CI: 2.11-2.50). These rates were stable over time. Despite clear guidelines of a 2-week target, several studies have demonstrated that this target is not met. Up to $40 \%$ of patients do not have their CEA performed within 2 weeks of symptom onset (19). The reason for this has been multifactorial. They include a delay in access to carotid imaging, long waiting times to theatre, delay in referral to a vascular surgeon, delays resulting from co-morbidities and a delay in patients seeking medical help (20-27). Studying trends reported in the UK National Vascular Registry from 2009-2014 found the most common delays to be referral to a vascular surgeon, followed by delay in the patient seeking medical attention after symptom onset and a delay in access to carotid imaging (19). The delay times and rank order of delay reasons had not changed in the last 3 years of the study period. The most recent NVR 2019 report outlined the median time from symptom onset to CEA was 12 days (IQR, 7-23 days) (28). Only $60 \%$ of patients were treated within 2 weeks. The median delay times were 4 days (IQR, 1-9 days) from symptom to referral; 1 day (IQR, 0-5 days) from referral to vascular surgeon review; 5 days (IQR, 2-10 days) from vascular surgeon review to CEA (28).

The specific question of timing of intervention and safety of early CEA has now been investigated in several studies beyond the two seminal RCTs and their subanalyses. No statistical difference in periprocedural stroke rates were found in an international multicentre study analysing 145 CEAs performed urgently or early. Groups divided into urgent (CEA $<48$ hours from index cerebral event) and early (3-14 days to CEA from index cerebral event) were similar in their stroke rate $(10.0 \%$ vs. $4.1 \%$; $\mathrm{P}=0.260$ ) (29). CEAs performed across 4 different time periods from symptom onset $(0-2,3-7,8-14$ and $>14$ days) did not influence peri-operative outcome in a multivariate analysis of 761 symptomatic patients [odds ratio (OR) 0.93 (0.63-1.36), $\mathrm{P}=0.71]$ (30). The majority of patients in this study had initial non-disabling events (admission Rankin score $<2$ in over $90 \%$ of patients). The same finding was observed in patients with severe neurological disability from the index event (Rankin score $>1$ ), with a composite stroke and death rate of $4.4 \%, 1.8 \%, 4.4 \%$ and $2.5 \%$ in patients undergoing CEA at $0-2,3-7,8-14$ and $>14$ days respectively (30). The National Norwegian Carotid Study examined almost all (99.2\%) patients undergoing CEA in 
Norway between April 2014 and March 2015 (31). The composite outcome of 30-day stroke/death rates for CEA within 48 hours, 3-7 days, $8-14$ days and $>14$ days from index event to operation were $0 \%, 3.4 \%, 5.4 \%$ and $2.8 \%$ respectively (31). No statistical difference was observed in the complication rate in urgent versus early CEA groups in this prospective population study. Ferrero et al. also found relatively acceptable perioperative stroke rates for CEAs performed within 48 hours. The study investigated 285 patients in 5 treatment groups (CEA within $<48$ hours, 48 hours-2 weeks, $2-4$ weeks, $4-8$ weeks, $8-24$ weeks). The stroke rate amongst $<48$ hour group was $4.2 \%$ which did not differ statistically from the other groups ( $48 \mathrm{~h}-2$ weeks $=3.2 \% ; 2-4$ weeks $=0 \% ; 4-8$ weeks $=3.4 \% ; 8-24$ weeks $=3.8 \%$ ) (32). In this study, patients were not eligible for CEA if they presented with a disabling neurological event (modified Rankin score $>5$ ), cerebral lesion greater than $3 \mathrm{~cm}$, suspected or confirmed parenchymal haemorrhage associated with infarct, occlusion of the middle cerebral artery or considered unfit for surgery (American Society of Anaesthesia classification grade V). The authors concluded that performing CEA within 48 hours is safe in appropriately selected patients with non-disabling stroke. Ferrero et al. also reported on a series of 176 patients in 2014 investigating the perioperative risk of urgent CEA differentiated by presenting neurological feature-TIA, crescendo TIA (cTIA) and stroke in evolution (SIE). The stroke/MI death rates at 30 days were $1.8 \%$ (TIA), $0 \%$ (cTIA) and $7.6 \%$ (SIE). The higher complication rate in SIE was not statistically significant in comparison to TIA and cTIA in this study (33).

The argument that performing CEA within 2 weeks is both safe and beneficial has now been well established. Although favourable results have been published for urgent CEA, concerns have been reported in the periprocedural risk associated with urgent CEA ( $<48$ hours) compared to early CEA (within 2 weeks). The Swedish Vascular Registry reported 2,596 CEAs performed for symptomatic carotid artery stenosis between May 2008 and May 2011. According to time to CEA from the neurological event, patients were investigated across 4 groups $(0-2,3-7,8-14$ and 15-180 days). The corresponding combined stroke/death rate was found to be $11.5 \%$ ( $0-2$ days), 3.6\% (3-7 days), $4.0 \%$ (8-14 days) and 5.4\% (15-180 days). Over a 4 fold increase risk of stroke/death was seen between the 0-2 day group and 3-7 day group (OR: 4.24; 95\% CI: 2.07-8.70; $\mathrm{P}<0.001)$ (34). Further reports from Sweden on the Carotid Alarm Study published in 2017 highlighted similar concerns regarding urgent CEA. Prospectively studying 418 patients, multivariate regression analysis identified urgent CEA ( $<48$ hours) as an independent risk factor for death and stroke within 30 days of CEA (35). Urgent CEA conferred an $8.0 \%$ risk of death or stroke versus $2.9 \%$ for the $2-14$-day group. The Vascular Study Group of New England (VSGNE) studied outcomes from 989 patients identified in their database undergoing symptomatic CEA. Four groups according to timing of surgery were identified-group 1, $<2$ days; group 2, 2-5 days; group 3, $\geq 6$ days; group 4, same day CEA. Stroke rates after CEA were highest in group $1(7.3 \% ; \mathrm{P}=0.016)$ (36). Other adverse outcomes were comparable amongst groups. De Rango et al. published a systematic review and meta-analysis in 2015 of 47 studies investigating carotid revascularisation and timing of intervention (37). Of the included studies, 35 were CEA, 7 on carotid artery stenting and 5 included both. The pooled estimate periprocedural stroke risk for TIA subgroup of patients was $2.7 \%$ for CEA within 48 hours, $1.5 \%$ for CEA between $0-7$ days and $1.6 \%$ for CEA $<15$ days (37). However, when analysing patients presenting initially with stroke as the index neurological event, the CEA periprocedural stroke risk is much higher, particularly for the urgent group ( $<48$ hours): $8.0 \%$ ( $<48$ hours), $5.3 \%$ (0-7 days), $5.0 \%$ (0-15 days) (37). Villwock et al. studied the National Inpatient Sample database between 2002 and 2011, including 59,327 patients having a CEA (38). Rates of stroke/TIA were analysed for CEA performed within 48 hours or deferred (48 hours-14 days) and according to the presence or absence of cerebral infarction. Within 48 hours, the death and stroke rates were $1.3 \%$ and $1.7 \%$ respectively for infarction, versus $0.4 \%$ and $1.1 \%$ without infarction. The death and stroke rates for CEA between 48 hours and 14 days were $0.9 \%$ and $1.3 \%$ respectively with infarction, versus $0.8 \%$ and $1.8 \%$ without infarction. The death and perioperative stroke rates were very favourable in this study, however the authors do note that performing urgent ( $<48$ hours) CEA for patients with infarction is associated with a small increase in mortality and stroke perioperatively (39).

The risks of perioperative complications with urgent CEA has to be contextualised further with the state of modern medical therapy. Earlier studies quantifying the risk of recurrent stroke in symptomatic carotid artery stenosis may have been overestimated in comparison to the contemporary strategy of intensive medical therapy with dual antiplatelets and statins. Aggressive medical therapy with dual antiplatelets and statins reduces the recurrent risk of an 
early ischaemic event prior to undergoing a CEA (40-42). A 5-fold reduction in recurrent neurological events prior to CEA has been shown with aggressive medical therapy (42). Recent data demonstrated the risk of recurrent early neurological event with dual antiplatelet therapy and statin pharmacotherapy is reduced to $2.0 \%$ within 2 days, $4 \%$ within 7 days and $7.5 \%$ within 30 days (41). The role medical therapy in the timing of CEA is still debated, particularly given that the Management of A Therothrombosis with Clopidogrel in High-risk Patients (MATCH) trial failed to demonstrate the superiority of dual antiplatelets versus clopidogrel monotherapy (43).

The National Institute of Clinical Excellence (NICE) recommends time from symptom to intervention within 14 days (44). The United Kingdom National Vascular Registry reported the median time to intervention was 12 days (IQR, 7-23 days) in 2018 (45). Between 2016 and 2018, The UK national operative (within 30 days) death and/or stroke rate was $2 \%$ (45). The evidence has now been well established in performing early CEA (within 2 weeks) maximising stroke free survival from recurrent ischaemic events and has an established safety profile in terms of peri-procedural complications. Although there is a relative balance of evidence in the literature for urgent CEA (within 48 hours), the periprocedural risks still remain a concern, with complications exceeding 2\% for urgent CEA in studies reporting the effect of timing on surgical complications. This seems to be particularly the case when performing CEAs on patients with significant neurology and stroke as the index event. Careful patient selection, presenting neurology and medical therapy is likely to be a key feature in considering urgent CEA versus early CEA.

\section{Acknowledgments}

Funding: None.

\section{Footnote}

Provenance and Peer Review: This article was commissioned by the Guest Editor (Dr. Kosmas I. Paraskevas) for the series "Carotid Artery Stenosis and Stroke: Prevention and Treatment Part I" published in Annals of Translational Medicine. The article was sent for external peer review organized by the Guest Editor and the editorial office.

Conflicts of Interest: All authors have completed the ICMJE uniform disclosure form (available at http://dx.doi. org/10.21037/atm-20-1130). The series "Carotid Artery Stenosis and Stroke: Prevention and Treatment Part I" was commissioned by the editorial office without any funding or sponsorship. The authors have no other conflicts of interest to declare.

Ethical Statement: The authors are accountable for all aspects of the work in ensuring that questions related to the accuracy or integrity of any part of the work are appropriately investigated and resolved.

Open Access Statement: This is an Open Access article distributed in accordance with the Creative Commons Attribution-NonCommercial-NoDerivs 4.0 International License (CC BY-NC-ND 4.0), which permits the noncommercial replication and distribution of the article with the strict proviso that no changes or edits are made and the original work is properly cited (including links to both the formal publication through the relevant DOI and the license). See: https://creativecommons.org/licenses/by-nc-nd/4.0/.

\section{References}

1. World Stroke Organisation. Global Stroke Fact Sheet. Website. Available online: https://www.worldstroke.org/ assets/downloads/WSO_Global_Stroke_Fact_Sheet.pdf. Accessed on: 16 Mar 2020.

2. Mihindu E, Mohammed A, Smith T, et al. Patients with moderate to severe strokes (NIHSS score $>10$ ) undergoing urgent carotid interventions within 48 hours have worse functional outcomes. J Vasc Surg 2019;69:1471-81.

3. Randomised trial of endarterectomy for recently symptomatic carotid stenosis: Final results of the MRC European Carotid Surgery Trial (ECST). Lancet 1998;351:1379-87.

4. Ferguson GG, Eliasziw M, Barr HWK, et al. The North American Symptomatic Carotid Endarterectomy Trial Surgical Results in 1415 Patients. Stroke 1999;30:1751-8.

5. Biller J, Feinberg WM, Castaldo JE, et al. Guidelines for carotid endarterectomy: a statement for healthcare professionals from a Special Writing Group of the Stroke Council, American Heart Association. Circulation 1998;97:501-9.

6. Naylor AR. Delay May Reduce Procedural Risk, But at What Price to the Patient? Eur J Vasc Endovasc Surg 2008;35:383-91.

7. Loftus IM, Paraskevas KI, Naylor AR. Urgent Carotid Endarterectomy Does Not Increase Risk and Will Prevent 
More Strokes. Angiology 2017;68:469-71.

8. Rothwell PM, Eliasziw M, Gutnikov SA, et al. Endarterectomy for symptomatic carotid stenosis in relation to clinical subgroups and timing of surgery. Lancet 2004;363:915-24.

9. Giles MF, Rothwell PM. Risk of stroke early after transient ischaemic attack: a systematic review and meta-analysis. Lancet Neurol 2007;6:1063-72.

10. Ois A, Cuadrado-Godia E, Rodríguez-Campello A, et al. High risk of early neurological recurrence in symptomatic carotid stenosis. Stroke 2009;40:2727-31.

11. Gasecki AP, Ferguson GG, Eliasziw M, et al. Early endarterectomy for severe carotid artery stenosis after a nondisabling stroke: Results from the North American Symptomatic Carotid Endarterectomy Trial. J Vasc Surg 1994;20:288-95.

12. North American Symptomatic Carotid Endarterectomy Trial Collaborators, Barnett HJM, Taylor DW, et al. Beneficial Effect of Carotid Endarterectomy in Symptomatic Patients with High-Grade Carotid Stenosis. N Engl J Med 1991;325:445-53.

13. Warlow CP, Whisnant JP. MRC European carotid surgery trial: Interim results for symptomatic patients with severe (70-99\%) or with mild (0-29\%) carotid stenosis. Ann Intern Med 1991;115:33-4.

14. Mayberg MR, Wilson SE, Yatsu F, et al. Carotid endarterectomy and prevention of cerebral ischemia in symptomatic carotid stenosis. Veterans Affairs Cooperative Studies Program 309 Trialist Group. JAMA 1991;266:3289-94.

15. Naylor AR. Time is brain! Surgeon 2007;5:23-30.

16. Furie KL, Kasner SE, Adams RJ, et al. Guidelines for the prevention of stroke in patients with stroke or transient ischemic attack: A guideline for healthcare professionals from the American Heart Association/American stroke association. Stroke 2011;42:227-76.

17. Liapis CD, Bell SPRF, Mikhailidis D, et al. ESVS Guidelines. Invasive Treatment for Carotid Stenosis: Indications, Techniques. Eur J Vasc Endovasc Surg 2009;37:1-19.

18. Department of Health. National Stroke Strategy. Available online: www.dh.gov.uk/publications. Accessed on 16 Mar 2020.

19. Loftus IM, Paraskevas KI, Johal A, et al. Delays to Surgery and Procedural Risks Following Carotid Endarterectomy in the UK National Vascular Registry. Eur J Vasc Endovasc Surg 2016;52:438-43.

20. Kulkarni SR, Gohel M, Bulbulia RA, et al. The importance of early carotid endarterectomy in symptomatic patients. Ann R Coll Surg Engl 2009;91:210-3.

21. Vikatmaa P, Sairanen T, Lindholm JM, et al. Structure of Delay in Carotid Surgery--An Observational Study. Eur J Vasc Endovasc Surg 2011;42:273-9.

22. Purkayastha D, Grant S, Smyth JV, et al. Delayed carotid surgery: what are the causes in the north west of England? Eur J Vasc Endovasc Surg 2012;43:637-41.

23. Dyer E, Lownie S, Ferguson G. Wait times for carotid endarterectomy, London Ontario 2006-2007. Can J Neurol Sci 2013;40:330-3.

24. Gaba KA, Syed MJB, Raza Z. Reducing the delay for carotid endarterectomy in South-East Scotland. Surgeon 2014;12:11-6.

25. Halliday AW, Lees T, Kamugasha D, et al. Waiting times for carotid endarterectomy in UK: observational study. BMJ 2009;338:b1847.

26. Guest RV, Chalmers RTA. Carotid Endarterectomy: Are We Meeting the Two Week Target? Scot Med J 2009;54:27-9.

27. Gladstone DJ, Oh J, Fang J, et al. Urgency of carotid endarterectomy for secondary stroke prevention: results from the Registry of the Canadian Stroke Network. Stroke 2009;40:2776-82.

28. Waton S, Johal A, Heikkila K, et al. National Vascular Registry: 2019 Annual report. London: The Royal College of Surgeons of England, November 2019. Available online: https://www.vsqip.org.uk/content/uploads/2019/12/NVR2019-Annual-Report.pdf. Accessed on: 16 Mar 2020.

29. Tsivgoulis G, Krogias C, Georgiadis GS, et al. Safety of early endarterectomy in patients with symptomatic carotid artery stenosis: An international multicenter study. Eur J Neurol 2014;21:1251-7.

30. Rantner B, Schmidauer C, Knoflach M, et al. Very urgent carotid endarterectomy does not increase the procedural risk. Eur J Vasc Endovasc Surg 2015;49:129-36.

31. Kjørstad KE, Baksaas ST, Bundgaard D, et al. The National Norwegian Carotid Study: Time from Symptom Onset to Surgery is too Long, Resulting in Additional Neurological Events. Eur J Vasc Endovasc Surg 2017;54:415-22.

32. Ferrero E, Ferri M, Viazzo A, et al. Early carotid surgery in patients after acute ischemic stroke: Is it safe? A retrospective analysis in a single center between early and delayed/deferred carotid surgery on 285 patients. Ann Vasc Surg 2010;24:890-9.

33. Ferrero E, Ferri M, Viazzo A, et al. A retrospective study on early carotid endarterectomy within 48 hours after 
transient ischemic attack and stroke in evolution. Ann Vasc Surg 2014;28:227-38.

34. Strömberg S, Gelin J, Österberg T, et al. Very urgent carotid endarterectomy confers increased procedural risk. Stroke 2012;43:1331-5.

35. Nordanstig A, Rosengren L, Strömberg S, et al. Very Urgent Carotid Endarterectomy is Associated with an Increased Procedural Risk: The Carotid Alarm Study. Eur J Vasc Endovasc Surg 2017;54:278-86.

36. Avgerinos ED, Farber A, Abou Ali AN, et al. Early carotid endarterectomy performed 2 to 5 days after the onset of neurologic symptoms leads to comparable results to carotid endarterectomy performed at later time points. J Vasc Surg 2017;66:1719-26.

37. De Rango P, Brown MM, Chaturvedi S, et al. Summary of evidence on early carotid intervention for recently symptomatic stenosis based on meta-analysis of current risks. Stroke 2015;46:3423-36.

38. Villwock MR, Singla A, Padalino DJ, et al. Stenting versus endarterectomy and the impact of ultra-early revascularization for emergent admissions of carotid artery stenosis. J Stroke Cerebrovasc Dis 2014;23:2341-9.

39. Villwock MR, Singla A, Padalino DJ, et al. Optimum timing of revascularization for emergent admissions of carotid artery stenosis with infarction. Clin Neurol Neurosurg 2014;127:128-33.

40. Shahidi S, Owen-Falkenberg A, Gottschalksen B,

Cite this article as: Azhar B, Wafi A, Budge J, Loftus I. Timing of carotid endarterectomy and clinical outcomes. Ann Transl Med 2020;8(19):1267. doi: 10.21037/atm-20-1130 et al. Risk of early recurrent stroke in symptomatic carotid stenosis after best medical therapy and before endarterectomy. Int J Stroke 2016;11:41-51.

41. Strömberg S, Nordanstig A, Bentzel T, et al. Risk of early recurrent stroke in symptomatic carotid stenosis. Eur J Vasc Endovasc Surg 2015;49:137-44.

42. Batchelder A, Hunter J, Cairns V, et al. Dual Antiplatelet Therapy Prior to Expedited Carotid Surgery Reduces Recurrent Events Prior to Surgery without Significantly Increasing Peri-operative Bleeding Complications. Eur J Vasc Endovasc Surg 2015;50:412-9.

43. Diener HC, Bogousslavsky J, Brass LM, et al. Aspirin and clopidogrel compared with clopidogrel alone after recent ischaemic stroke or transient ischaemic attack in high-risk patients (MATCH): Randomised, double-blind, placebocontrolled trial. Lancet 2004;364:331-7.

44. National Institute of Clincal Excellence. Stroke and transient ischaemic attact in over 16s: diagnosis and initial management. [Internet]. [London]. NICE; 2019 [updated May 2019; cited 2020 Jan 29]. (NICE guidline [NG128]). Available online: https://www.nice.org.uk/guidance/ng128. Accessed on 16 Mar 2020.

45. Vascular Society of Great Britain and Ireland. National Vascular Registry 2018 Annual Report [Internet] 2018. Available online: https://www.vsqip.org.uk/content/ uploads/2019/07/2018-NVR-Annual-Report.pdf. Accessed on 16 Mar 2020. 